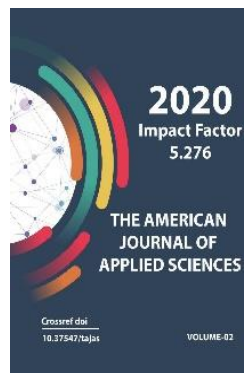

\title{
Agricultural Measures In Soil Effect On Nutrition
}

\author{
Saidakhon Bakhodirbekovna Mamadalieva \\ Assistant Of The Department Of Botany, Soybeans And Oilseeds, Uzbekistan \\ Zuhriddin Muminovich Jumaboev \\ Associate Professor Of Agricultural Sciences Head Of The Department Of Botany, Soybeans \\ And Oilseeds, Andijan Institute Of Agriculture And Agrotechnology Uzbekistan
}

\section{ABSTRACT}

Results of scientific substantiation and introduction of optimal nutritional norms,seedling thickness and water consumption in the production of fairy-tale, high- quality cotton crop of UzPITI-201 cotton cultivated in the technology of sowing seeds under the film, which is a key element of accelerated saving technologies in light gray soils of Andijan region listed.

\section{KEYWORDS}

Fertilizer, crop, cotton-plant, phosphorus, potassium, nitrogen, humus, nutrients, film.

\section{INTRODUCTION}

It is known that in the cultivation of cotton plants planting scheme, fertilizer standards and irrigation regimes have been found to have a positive effect on the ripening of pods, the technological qualities of fiber and other characteristics of the plant.

UzPITI-201 cotton variety was fed in different fertilizer rates, and when irrigated in different regimes, the action of nutrients in the soil and their assimilation by the plant was unique. In the experimental variants, soil samples were taken at the beginning of the application

period, during the mowing, flowering and ripening stages, to observe the movement of nutrients and determine their effectiveness.

\section{THE MAIN RESULTS AND FINDINGS}

According to the results of the study for an average of 3 years, the agrophysical and agrochemical properties of the soil in variants $1-7$, planted in the first sowing period (5.03- 
10.03) of cotton variety UzPITI-201 had an impact on various processes in the soil, directly related to soil temperature, humidity and air temperature. . In particular, according to the analysis of the total amount of nutrients in the soil, no changes were observed in the laws of exposure of agricultural measures to nutrients in the samples at the beginning of the application period (Table 1). At the end of the application period, in the control variant (options 1-2), planted in the usual open method and applied NRK-200-140-100 annual norms of mineral fertilizers per hectare, humus was 0.08-0.09 compared to the beginning of the application period; nitrogen and phosphorus in the general form were reduced by $0.005-0.006$ and $0.005 \%$, respectively. This is due to the fact that in these warrants the soil moisture at the beginning of the growing season, insufficient factors that positively affect the movement of nutrients, low nutrient consumption in the early spring due to low temperature and soil conditions and other external factors (Table 2 ).

Also, in the control option (option 3) NRK-200140-100 annual norms of fertilizer per hectare were applied as a mulch between the rows as mulch between rows during cotton weeding. Under favorable soil temperature and humidity conditions, nutrient consumption decreased and humus content in the soil driving layer $(0-30 \mathrm{~cm}) \quad 0.02$; nitrogen increased by 0.003 and phosphorus by $0.002 \%$. Exactly the same patterns are observed in the second period (20.03-25.03) of seeds of cotton variety UzPITI-201 in variants $8-9$, planted in open ground at a comfortable soil and air temperature. 09; nitrogen and phosphorus in the general form were reduced by $0.005^{-}$ 0.006 and $0.005 \%$, respectively. It should be noted that the seeds of UzPITI-201 cotton variety were sown in the open in the second period (options 8-9), compared to the first sowing period due to a significant increase in the effectiveness of mineral fertilizers at favorable soil moisture and temperature, favorable weather conditions. a relative decrease in nutrient consumption was observed in the options.

Also, in the control variant (Option 3), which was covered with a black film as mulch between rows and applied mineral fertilizers at the rate of NRK-200-140-100 per hectare, the consumption of nutrients under favorable soil temperature and humidity decreased the amount of humus in the soil driving layer (0-30 $\mathrm{cm}$ ) is 0.04 , the nutrients increased by $1.5-2.0$ times compared to the first sowing period of the variety; nitrogen increased by 0.007 and phosphorus by $0.005 \%$. It should be noted that studies have shown that the concentration of carbon dioxide and methane gases in the air of soils covered with polyethylene film is higher than in soils without film. As a result of biochemical reactions under the film, carbon dioxide reacts with water to form carbonic acid ( $\mathrm{N}_{2} \mathrm{SO}_{3}$ ), while methane gas forms acetic acid (SN3SOON) as a result of biochemical reactions under the film. They, in turn, combine with two and three calcium phosphate acids to form one-calcium phosphorus salts in easily soluble and easily assimilated forms by the plant root. As a result, the efficiency of the use of mineral fertilizers increases. Accordingly, during both sowing seasons of UzPITI-201 cotton variety, the movement of nutrients in the buds covered with black and transparent film was accelerated, and even in the variants with reduced fertilizer rates, a significant increase in the efficiency of mineral fertilizers was observed. At the same time, significant differences were observed between sowing periods, and in early (8.03) planted variants (variants 1-7) there was a significant decrease in their amount due to the lack of nutrient movement at low soil and air temperatures in the early stages of cotton development.

Now, if we talk about double-row and singlerow variants (variants 4-7 and 10-14) of UzPITI- 
201 cotton seedlings under a transparent film, the seeds are sown early in the first term variants (variants 1-7) at the beginning of the validity period $0-30 . \mathrm{cm}$ found that the humus content in the soil driving layer was $0.693 \%$. At the end of the application period, under the positive influence of the above-mentioned soil environment under the film, the amount of humus in the seeds planted in double rows (options 4-5) increased by $0.01-0.02 \%$, in singlerow planted options (options 6-7) 0.01 increased by\%. In other words, no reduction in nutrients was observed in these options, but the soil fertility was maintained at its previous state. A similar pattern was observed in the action of nitrogen and phosphorus nutrients in their general form. For example, at the beginning of the application period, $0-30 \mathrm{~cm}$ of soil in the driving layer was 0.069 and $0.162 \%$, respectively, and at the end of the application period there was an increase of 0.001 and $0.003 \%$ in double rows and a decrease of $0.001 \%$ in single rows (Table 2 ). Seeds of UzPITI-201 cotton variety were sown in double rows and single rows under a transparent film in the second period (options 11-14) at the beginning of the application period with a humus content of $0.693 \%$ in the soil layer of $0-30 \mathrm{~cm}$ at the beginning of the application period.

Table 1.

The effect of agronomic measures on the amount of nutrients in general form at the beginning of the application period,\% average 3 years

(2016-2018yy).

\begin{tabular}{|c|c|c|c|c|}
\hline \multirow{2}{*}{ Variations } & \multicolumn{2}{|l|}{$\begin{array}{c}\text { Soil layer, } \\
\text { sm }\end{array}$} & \multicolumn{2}{l|}{ At the beginning of the period } \\
\cline { 3 - 5 } & & Гумус & А30т & Фосфор \\
\hline $\begin{array}{c}\text { Normal open sowing, 1-2, } \\
\text { 9-10 (control) }\end{array}$ & $0-30$ & 0,698 & 0,075 & 0,161 \\
\cline { 2 - 5 } & $30-50$ & 0,672 & 0,062 & 0,152 \\
\hline Black film 4, 12 (control) & $0-30$ & 0,702 & 0,077 & 0,169 \\
\cline { 2 - 5 } & $30-50$ & 0,687 & 0,070 & 0,150 \\
\hline Transparent film, 3, 5-8, 11, & $0-30$ & 0,693 & 0069 & 0162, \\
\cline { 2 - 5 } & $30-50$ & 0,681 & 0,067 & 0,154 \\
\hline
\end{tabular}


Table 2.

The effect of agronomic measures on the amount of nutrients in the total form at the end of the application period,\% average 3 years

(2016-2018yy).

\begin{tabular}{|c|c|c|c|c|c|c|c|c|}
\hline \multirow{2}{*}{$\begin{array}{l}\text { VAR. } \\
\text { № }\end{array}$} & \multirow{2}{*}{$\begin{array}{l}\text { Planting } \\
\text { method }\end{array}$} & \multirow{2}{*}{$\begin{array}{c}\text { Getting rid } \\
\text { of }\end{array}$} & \multicolumn{2}{|c|}{ Humus. } & \multicolumn{2}{|c|}{ Nitrogen } & \multicolumn{2}{|c|}{ Phosphorus } \\
\hline & & & $0-30$ & $30-50$ & $0-30$ & $30-50$ & $0-30$ & $30-50$ \\
\hline 1 & Open & Double row & 0,689 & 0,664 & 0,069 & 0,063 & 0,156 & 0,147 \\
\hline 2 & Open & Double row & 0,690 & 0,671 & 0,067 & 0,062 & 0,157 & 0,147 \\
\hline 3 & Black film & Single row & 0,704 & 0,690 & 0,083 & 0,074 & 0,173 & 0,153 \\
\hline 4 & Transparent film & Double row & 0,694 & 0,682 & 0,071 & 0,072 & 0,163 & 0,157 \\
\hline 5 & Transparent film & Double row & 0,695 & 0,685 & 0,072 & 0,063 & 0,164 & 0,156 \\
\hline 6 & Transparent film & Single row & 0,693 & 0,681 & 0,070 & 0,074 & 0,160 & 0,158 \\
\hline 7 & Transparent film & Single row & 0,694 & 0,684 & 0,068 & 0,070 & 0,165 & 0,156 \\
\hline 8 & Open & Double row & 0,692 & 0,665 & 0,066 & 0,054 & 0,154 & 0,146 \\
\hline 9 & Open & Double row & 0,690 & 0,667 & 0,065 & 0,052 & 0,155 & 0,147 \\
\hline 10 & Black film & Single row & 0,706 & 0,691 & 0,084 & 0,077 & 0,174 & 0,156 \\
\hline 11 & Transparent film & Double row & 0,698 & 0,686 & 0,075 & 0,074 & 0,165 & 0,161 \\
\hline 12 & Transparent film & Double row & 0,696 & 0,685 & 0,077 & 0,075 & 0,166 & 0,160 \\
\hline 13 & Transparent film & Single row & 0,697 & 0,689 & 0,072 & 0,073 & 0,164 & 0,160 \\
\hline 14 & Transparent film & Single row & 0,696 & 0,690 & 0,071 & 0,073 & 0,164 & 0,160 \\
\hline
\end{tabular}

Under the positive influence of the soil environment under the mentioned film, it was observed that the amount of humus in the seeds planted in double rows (options 11-12) increased by $0.05-0.03 \%$, in single row planted options (options 13-14) by $0.03 \%$. In other words, no decrease in nutrients was observed in these options either, but an increase in soil fertility was achieved under the positive influence of favorable weather conditions, soil moisture and temperature in the next period. A similar pattern was observed in the movement of nitrogen and phosphorus nutrients in general form, which at the beginning of the application period was 0.069 and $0.162 \%$, respectively, in the $0-30 \mathrm{~cm}$ soil layer, while at the end of the application period it increased by 0.003 and $0.002 \%$ in double rows and 0.001 in single rows. decreased by\%. The same patterns were observed in the mobile forms of nutrients, and under the positive influence of favorable soil conditions under the transparent film during the second sowing period, the amounts of mobile nutrients increased in accordance with agro-measures. At the beginning of the validity period of the first planting period, a decrease in soil and air temperature in all variants was observed to have a negative effect on the activity of mobile nutrients. As a result, in these variants (variants 1-7) the nutrients decreased compared to the second sowing period. This was also reflected in the 
later stages of growth and development of cotton.

According to the results of the average threeyear study, the seeds of the second sowing period were fertilized in the open double row with mineral fertilizers NRK-200-140-100 kg per hectare in the control variant when nitrogen nutrients increased to $38.50-38.86 \mathrm{mg} / \mathrm{kg}$ during cotton flowering by the end of the application period, all were consumed and amounted to $24.80-23.64 \mathrm{mg} / \mathrm{kg}$. Phosphorus nutrients also increased until the flowering period of cotton, reaching 42.84-44.86 mg / $\mathrm{kg}$. By the end of the application period, a significant decrease was observed, with a reserve of $28.78-26.24 \mathrm{mg} / \mathrm{kg}$. So, we can say that in the method of open sowing of cotton, cotton grew only at the expense of mineral fertilizers. In the 10th control variant, where the annual norms of mineral fertilizers NRK200-140-100 kg per hectare were applied, the initial technology was similar to the 1-2 control variant, where the seeds were sown in the open, but the soil conditions under the film were irrigated with black film as mulch between rows. albeit for a short time, provided an increase in nutrients due to its positive effect on nutrient movement. For example, $38.86 \mathrm{mg} / \mathrm{kg}$ of nitrogen, $40.86 \mathrm{mg}$ / kg of phosphorus, and $220 \mathrm{mg} / \mathrm{kg}$ of potassium were accumulated during the flowering period of cotton, at the end of the application period, respectively, 22.60; 22.24 and $160 \mathrm{mg} / \mathrm{kg}$ of nutrients remained in reserve.

Also, in the second sowing period, the seeds were sown in double rows and the annual norms of mineral fertilizers NRK-180-125-90 kg per hectare were applied. an increase in the flowering period from 40.53 to $40.34 \mathrm{mg} / \mathrm{kg}$ was observed. By the end of the period, the active nitrogen was reduced by only $20 \%$ to $32.60-34.80 \mathrm{mg} / \mathrm{kg}$, respectively. It was also found that in the 13-14 variants planted in a single row under the film, the application period was $8.55-9.28 \mathrm{mg} / \mathrm{kg}$ at the beginning, and during the flowering period the nutrients increased to $36.41-35.90 \mathrm{mg} / \mathrm{kg}$. it should be noted that nutrients were also most concentrated in these variants, as the nutrient area in the 35-40 $\mathrm{cm}$-wide piles under the double-row transparent film was 30\% greater than in the single-row piles. It is known that the larger the volume of the pile, the faster the nitrification process due to the improvement of soil volume mass and porosity, as well as the increase in its moisture and heat capacity, and an increase in nutrients in the soil environment.

As for phosphorus nutrients, the same seeds were found to be present at 16.90 and 15.88 $\mathrm{mg} / \mathrm{kg}$ at the beginning of the application period in double-row planted variants (variants 11-12). By the time of flowering of cotton, an increase of 44.86 and $41.39 \mathrm{mg} / \mathrm{kg}$ was observed. At the end of the application period, it was found to be $35-40 \%$, at 26.24 and $28.19 \mathrm{mg} / \mathrm{kg}$, respectively. Regarding the exchangeable potassium, it should be noted that the field was in an intermediate position even under the influence of various factors, as the level of potassium supply was moderate.

\section{CONCLUSION}

In summary, although the patterns of establishment of agronomic measures were the same in variants 1-7, which were sown in the first decade of March during the first sowing period in the study years, the results were lower than in varieties 8-14, which were sown in the second sowing period in March 3.

It was also found that the most effective way to use mineral fertilizers in the technology of double-row and single-row sowing of seeds under the film, which is a key element of resource-saving technology in both planting periods, is to reduce the annual fertilization rate of cotton by $10-15 \%$. 


\section{REFERENCES}

1. Bezborodov. G.A., Yu.G.Bezborodov. The content of hydrocarbons in the range of ethylene in the air vozduxe serozemov. Improving agro-technologies for the care of cotton and winter wheat. Tashkent. 2003. Pp. 89-93.

2. Bezborodov GA .. Resource-saving, environmentally friendly technology of cotton irrigation..Problems of cotton and grain development. Tashkent. 2004, pp. 189-190.

3. Ochilov E., Kashkarov N. Fundamentals of scientific research in botany. I/ Namangan. 2007. 3-8-b.

4. Kuzibaev Sh., Abdullaev F. Agricultural machinery of cotton variety "Onkurgan1". Agriculture of Uzbekistan. 2010 №8, p.15.

5. http: // www IRRI.org site. V.1-10 